The present article highlights the diverse role of stem cells in normal kidney and renal cancer, with special emphasis on surface markers. Proteins such as CD105 and CD133 have been reported as being significant in clear cell renal cell carcinoma (ccRCC) cancer stem cells. The role of normal kidney progenitor cells and their surface markers is compared with the role of those surface markers in ccRCC. Subsequently, we state the current hypothesis about origin of tumour-initiating cells along with their clinical and prognostic potential in RCC. Finally, we present future perspectives with respect to recent studies.

Key words: tumour-initiating cells, cancer stem cells, renal cancer.

Contemp Oncol (Pozn) 2015; 19 (1A):

A44-A51

DOI: $10.5114 /$ wo. 2014.47128

\section{Biology of renal tumour cancer stem cells applied in medicine}

\author{
Damian Matak ${ }^{1,2^{*}}$, Lukasz Szymanski ${ }^{1,3^{*}}$, Cezary Szczylik ${ }^{1}$, Rafal Sledziewski ${ }^{1}$, \\ Fei Lian ${ }^{4}$, Ewa Bartnik ${ }^{3,5}$, Anna Sobocinska ${ }^{1,6}$, Anna M. Czarnecka ${ }^{1}$
}

${ }^{1}$ Department of Oncology with Laboratory of Molecular Oncology, Military Institute of Medicine, Warsaw, Poland

${ }^{2}$ School of Molecular Medicine, Medical University of Warsaw, Warsaw, Poland

${ }^{3}$ Institute of Genetics and Biotechnology, Faculty of Biology, University of Warsaw, Poland ${ }^{4}$ Emory School of Medicine Atlanta, GA, USA

Institute of Biochemistry and Biophysics, Polish Academy of Sciences, Warsaw, Poland

${ }^{6}$ Faculty of Biology, University of Warsaw, Poland

*Authors contributed equally to the work.

\section{Introduction}

The National Cancer Institute ( $\mathrm{NCl}$ ) defines renal cell cancer (RCC) as the most common type of kidney cancer, which begins in the lining of the renal tubules in the kidney [1]. The highest incidence of RCC was observed in the Czech Republic and North America [2]. Despite progress in general cancer diagnosis techniques, around $20-30 \%$ of patients are diagnosed with metastatic RCC (mRCC) and a further $20 \%$ will have a relapse after nephrectomy and develop mRCC in the first 12 months post-surgery. Current achievements in advanced RCC treatment are mainly due to molecular therapies targeting the vascular endothelial growth factor (VEGF) and mammalian target of rapamycin (mTOR). Angiogenesis plays a pivotal role in renal tumour growth since RCC is one of the most vascularised solid cancers, probably due to dysfunctional mutation in the von Hippel Lindau $(V H L)$ gene, which induces overexpression of hypoxia-inducible factor (HIF), and this leads to up-regulation of pro-angiogenic VEGF and platelet-derived growth factor (PDGF) $[3,4]$. Receptors for VEGF and PDGF play crucial roles in angiogenesis, mainly via cell survival, invasion, and proliferation, and exhibit tyrosine kinase activity. Tyrosine-kinase inhibitors (TKIs) were developed to block the physiological function of the receptors. Currently available TKIs approved by the Food and Drug Administration (FDA) in first and second or third line therapy are: sunitinib, pazopanib, sorafenib, and axitinib [5]. Bevacizumab, which is an anti-VEGF monoclonal antibody [3], is commonly used, with clinical benefit. Other new treatment strategies target the mTOR pathway, which is responsible for angiogenesis. Everolimus and temserolimus are mTOR inhibitors also approved by the FDA [5].

According to the latest hypothesis about cancer development and progression, "cancer stem cells" (CSCS) are responsible for cancer initiation and maintenance. Based on the definition, CSCS possess several features: clonogenic ability, expression of stem cell markers, lack of differentiation markers, multipotency, growth in non-adhesive spheroids, and most importantly generation of in vivo serially transplantable carcinomas that contain differentiated and undifferentiated cells. The tumourigenicity is analysed by generation of neoplasms after injection of a low number of cells into severe combined immune deficient (SCID) mice [6]. In the literature, the best tumour-generating cells were called CSCs, and the xenotransplantation causes inclusion of the analysed cell population into the CSCs class. The terminology in this case is inadequate - some other names have been postulated such as tumour-initiating cells (TICS), stemloids, or tumour propagating cells (TPCS). 
The CSC term suggests that its origin is from somatic stem cells, and that CSCs constitute a distinct population from other cancer cells. Stemloids [7] also exhibit similarities with somatic stem cells; however, this term suggests that stemloids and somatic stem cells are different. The operational term TIC [8] is linked to the cells that generate tumours in immunocompromised animals. Tumour-initiating cell suggests that the cells have initiated a tumour in vivo, which is not true - the cells have initiated a tumour after xenotransplantation. There is no clear confirmation which cancer cell population initiated the primary tumour in vivo, but current evidence indicates that it could only be from populations able to reconstitute a tumour in xenografts. On the basis of these facts, we support tumour-propagating cell (TPC) or tumour stem-like cell terms as better reflecting the features of cells mostly characterised by tumourigenicity potential in SCID mice in the literature. In our opinion these cells were improperly called CSCs.

The main aim of this article is to indicate inaccuracies within the terminology used for cells with stem-like features. Moreover, inconsistent data about proper identification and characterisation of renal cancer cells with stem-like features are discussed. Many techniques used to isolate the cells are compared and described within the article. At the beginning, the physiological role of the renal tumor-propagating cell markers (TPCS) is discussed to show putative connections with each marker and TPCS.
The next chapter describes the role of TPC markers in clinical patient prognosis to find new therapeutic targets. Finally, perspectives for new approaches to TPC identification and characterisation and new ideas that may change the direction of TPC research are described.

\section{Putative implications of renal tumour-propagating cell markers in cell physiology}

Molecular markers help support treatment planning because of more accurate individual risk assessment. Since the introduction of targeted therapies in RCC, more individualised treatment options have become available. Most of the TPCS in RCC research are isolated based on molecular markers that may play important physiological roles in the cell (Fig. 1). Molecular markers offer potential for additional information in tumour detection and diagnosis, prognostic and predictive values, as well as determination of therapeutic targets.

\section{CD105}

CD105 is a transmembrane protein expressed in angiogenic endothelial cells associated with proliferation and hypoxia (Fig. 2). Moreover, CD105 is a receptor for transforming growth factors TGF-1 and TGF-3. The exact molecular mechanisms of CD105 angiogenesis and vascular development are not fully understood [9]. CD105 is an integral

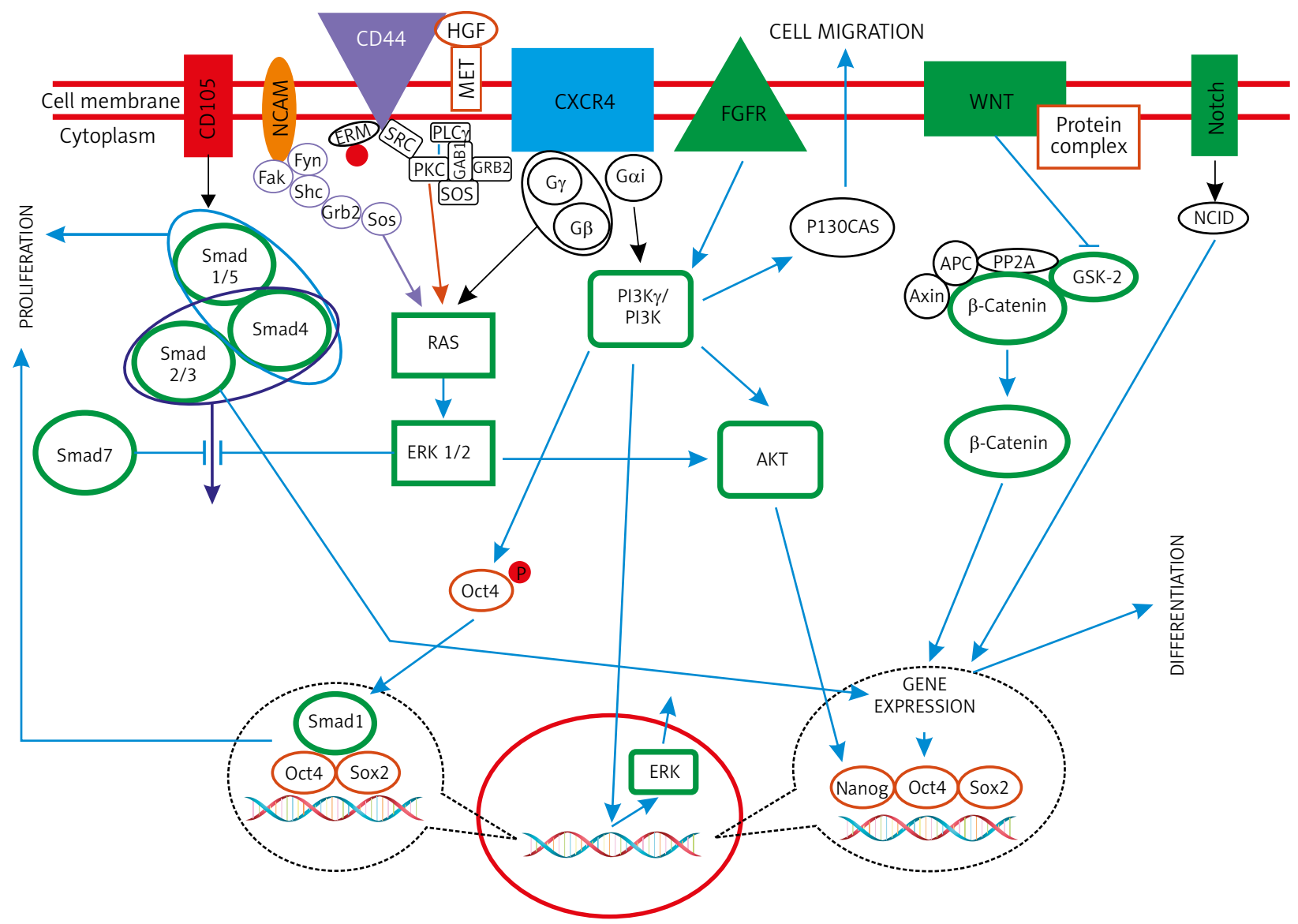

Fig. 1. The association of renal tumour-propagating cell markers in kidney development. Signalling pathways of kidney development is shown in green colour (frames and figures) 


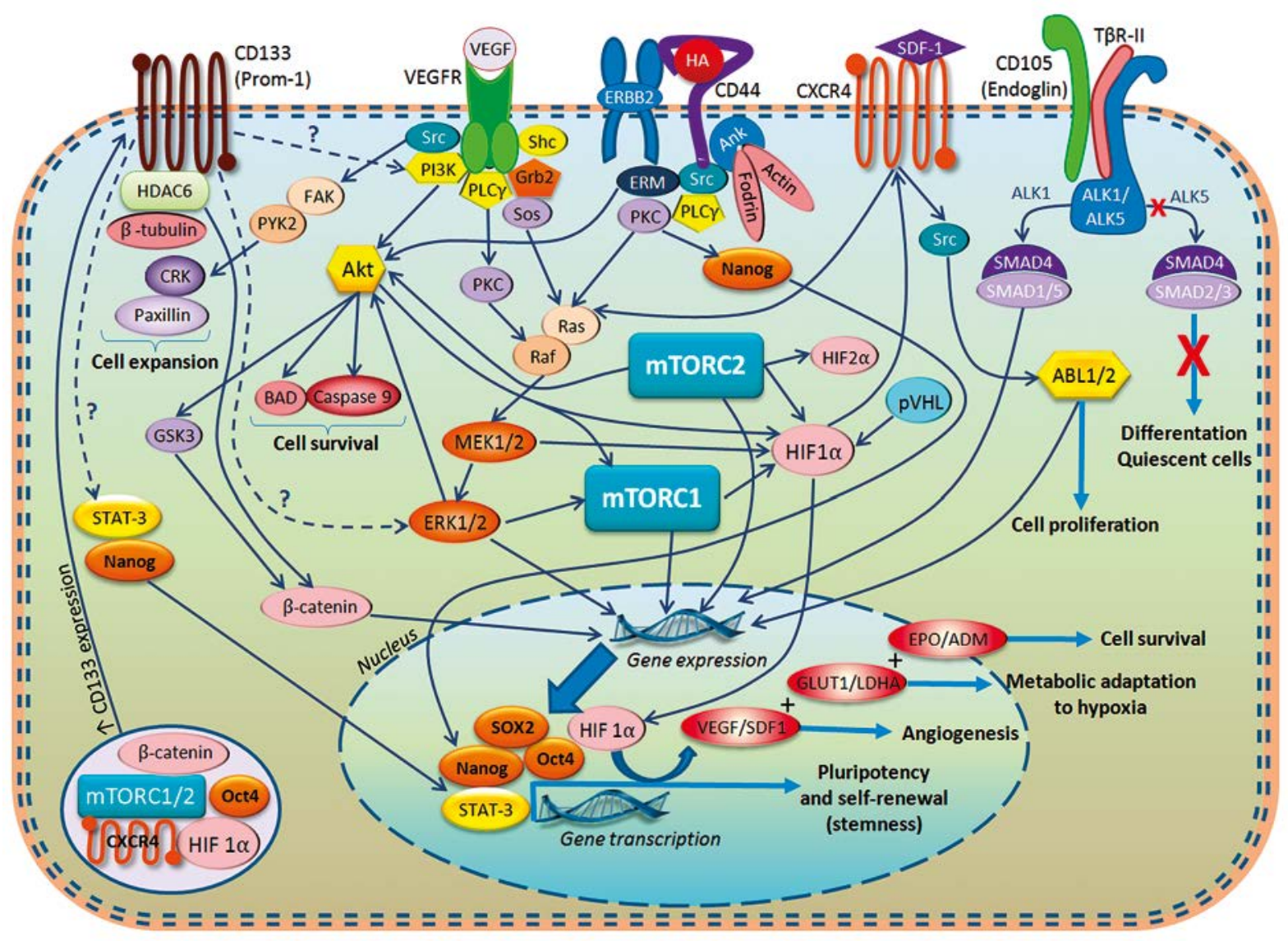

Fig. 2. Selected molecular pathways in renal tumour-propagating cells (TPCS). A view shows relations between a number of important regulators and markers that have been implicated in biology of renal cell cancer (RCC). The functions of some of the described receptors such us CD105 and CD133 still remain not well understood but are believed to play an essential role in many physiological and pathological processes. Specific for RCC proteins HIF1/2\&alpha and mTOR1/2 complex integrate crucial molecular routes taking part in tumorigenesis. Demonstrated pathways finally lead to gene expression and activation of transcription factors Oct4, SOX2, and Nanog, which are responsible for pluripotency maintenance and self-renewal of TPCs

membrane glycoprotein that is expressed primarily in the vascular endothelial cells of capillaries, arterioles, and venules, as well as in activated monocytes, some leukaemic cells, and the syncytiotrophoblast, the multinucleated placental layer that constitutes the interface with maternal blood [9-11]. Using gene knockout mice, CD105 was shown to play a major role in angiogenesis and vascular and cardiovascular development in early mouse embryos [12].

\section{CD133}

Prominin-1 or CD133 is a pentaspan membrane protein, whose specific functions are still unclear; however, it is believed that CD133 is an organiser of plasma membrane topology [13]. Interactions between cholesterol and CD133 suggest that CD133 plays a role in maintaining appropriate lipid concentrations within the plasma membrane $[14,15]$. Moreover, studies have confirmed CD133 as a marker of haematopoietic stem cells [16], but it is of importance that AC133 is expressed only on stem and progenitor cells, while CD133 is also expressed on differentiated cells [15]. CD133 in healthy cells is associated with tissue repair [17]. By a using a multiple tissue expression array, it was concluded that CD133 mRNA was strongly expressed in tissues such as adult kidney, mammary gland, trachea, salivary gland, placenta, pancreas, digestive tract, and testes [18]. Finally, recent findings show a relationship between CD133 and anaerobic cell metabolism; CD133 was shown to inhibit the endocytosis of the transferrin receptor, which resulted in the blockade of iron uptake and therefore of mitochondrial activity [19].

Studies have identified CD133 as a marker of CSC in various human tumours [20]; however, those cells did not show tumorigenic properties in xenotransplants in renal carcinomas, but significantly enhanced tumour growth and vascularisation [21, 22]. It has been theorised that in renal tumours, the microenvironment could recruit normal CD133 cells and promote their endothelial commitment [22].

\section{ALDH1}

Aldehyde dehydrogenase (ALDH1, ALDH1A1) is a cytosolic enzyme responsible for oxidation of intracellular aldehydes to carboxylic acids [23]. Aldehyde dehydrogenase in the cell is present, although in different isoforms, in mitochondria, cytoplasm, and the endoplasmic reticulum. Different isoforms of ALDH1 are distributed in various tissues, but the highest levels are observed in the liver and the kidney. Recently it has been stated that one of the main functions of ALDH1 is catalysis of retinol to retinoic acid 
conversion, and it has important role in embryonic development. High activity of ALDH has been shown in human and murine neural and haematopoietic stem and progenitor cells [24-27]. Multiple myeloma and acute myeloid leukaemia have been characterised with upregulated activity of ALDH in the stem cell population [28].

\section{CXCR4}

Chemokine receptor type 4 (CXCR4), the receptor for $\alpha$-chemokine stromal-derived factor (SDF-1), is very important in tumour biology, especially in tumour metastasis. Stromal-derived factor 1 is believed to be the mediator for many physiological and pathological processes via CXCR4. Chemokine receptor type 4 chemokine receptor belongs to the group of seven transmembrane $G$ protein-coupled receptors (GPCRs) that are ubiquitously expressed in various normal cells and tissues, including neurons, lymphatic tissues, microglia, and haematopoietic cells $[29,30]$. Chemokine receptor type 4 plays an important role in stem cell trafficking during development, tissue injury, and regeneration. Previous studies have shown that the chemokine receptor CXCR4 plays a role in breast and prostate cancer bone metastases via interactions with its ligand SDF-1 because of the role of SDF-1 in tumorigenesis and metastasis [31, 32]. As has been described in the case of other solid tumours, chemokine receptor CXCR4 is responsible for Src-mediated activation of $A B L$ kinases. It promotes cancer cell invasion by regulation of activity and localisation of matrix metalloproteinases (MMPs) as well as by modulation of gene expression of several MMPs and factors involved in EGFR-associated pathways [33, 34]. Downregulation of CXCR4 may prove to be a good therapeutic strategy for fighting tumour metastasis in patients with RCC.

\section{CD44}

CD44 is a cell adhesion molecule that seems to have a role in tumour cell invasion and tumour dissemination, by mediating interactions between tumour cells and their environment [35]. Altered expression of CD44 on tumour cells suggests a pathogenic mechanism for tumour metastasis and may provide prognostic information for particular tumours. CD44 is a surface transmembrane glycoprotein that was initially identified on lymphocytes. The extracellular domain of CD44 is the principal receptor of an extracellular matrix molecule, hyaluronic acid. Hyaluronic acid is a non-sulphated glycosaminoglycan that regulates cellular processes of adhesion, migration, and proliferation, and maintains extracellular matrix osmotic balance through its receptors, including CD44. There is a correlation between overexpression of hyaluronic acid and the metastatic potential of certain human tumours. Cell-matrix interactions of CD44 are related to tumour invasion and metastasis $[36,37]$.

\section{NCAM}

Neural cell adhesion molecule (NCAM) is a member of the immunoglobin superfamily (IgSF) of cell surface glycoproteins. It was detected for the first time in the neural system, where it plays a role in $\mathrm{Ca}^{2+}$-dependent cell adhesion. Neural cell adhesion molecule is an indicator of neuroendocrine differentiation of cells. Non-induced as well as induced foetal renal mesenchymal cells express NCAM as a specific cell surface antigen until they reach the perinatal period during kidney development in humans and rats. Induced mesenchymal cells rapidly loose expression of NCAM after the mesenchymal-epithelial transition on immature tubular cells during further differentiation of the nephron [38]. Re-expression of NCAM is detected during the regeneration process in some tubules [39] as well as in renal cell carcinoma (RCC) [40] and in RCC metastases in the central nervous system (CNS) and adrenal glands [41].

\section{Other markers}

Not all known molecular markers in RCC are described above. Other markers include, but are not limited to, vascular endothelial growth factor (VEGF), mammalian target of rapamycin (mTOR), survivin, $\mathrm{B} 7-\mathrm{H} 1, \mathrm{p} 53$, matrix metalloproteinases (MMP), insulin-like growth factor II mRNAbinding protein 3 (IMP3), Ki-67, FSP-1, C-reactive protein (CRP), vimentin, and fascin [42].

\section{The role of renal tumour-propagating markers in clinical prognosis}

Clear cell renal cell carcinoma is the most prevalent adult kidney tumour. Nowadays, prognoses are constructed using Fuhrman grade and stage. Those prognoses are not reliable and cCRCC is still a tumour of unpredictable presentation and clinical outcome [43]. Because of the need for reliable prognostic markers, promising targets such as CD133, CD105, and CXCR4 have been investigated (Fig. 3).

\section{CD105}

Endoglin (CD105) is a new marker of angiogenesis found to have prognostic value in various tumours, Dubinski et al. provided the first automated digital assessment of intratumoural microvascular density in cCRCC using CD105. According to their results CD105 is an unfavourable prognostic marker because patients with higher endoglin expression had significantly shorter PFS [44]. CD105 appears to be an interesting molecule, both as a predictive marker and therapeutic target; however, further investigation of its potential is needed.

\section{CD133}

D'Alterio et al. evaluated the role of two putative stem cell markers, CXCR4 and CD133, in 240 renal cancers. By using RT-PCR they concluded that CXCR4 was expressed in ten renal cancer cell lines, while CD133 was barely detectable. Moreover, expression of CD133 and CXCR4 was evaluated in 41 fresh RCC tumour samples. According to their results, in 31/41 samples CXCR4 mRNA was significantly upregulated, and in 7/41 samples CXCR4 expression was downregulated. CD133 mRNA was upregulated in 8/41 and downregulated in 28/41. After further evaluation of patient outcomes and expression of CXCR4 and CD133, D'Alterio et al. concluded that prognosis for patients 


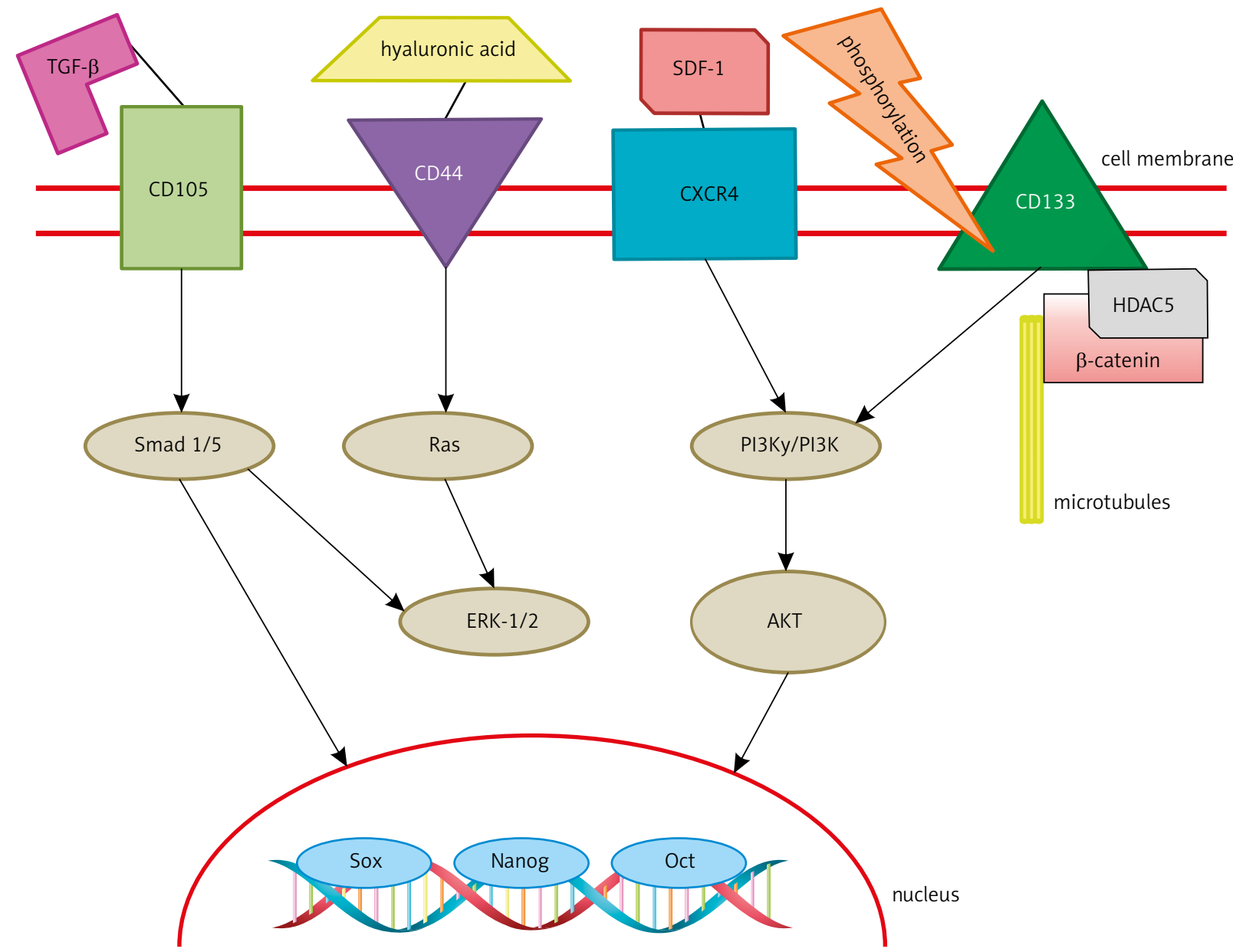

Fig. 3. The signalling pathway of renal tumour-propagating cell membrane markers and "cancer stem cell” markers

whose primary tumours express CXCR4 is unfavourable, while CD133 has no prognostic value [45]. Interestingly, Kim et al. examined the expression of CD133 in 140 cases of cCRCC using immunohistochemistry and found a correlation between expression of CD133 in cCRCC and favourable clinicopathological characteristics [46]. Moreover, Costa et al. evaluated the prognostic impact of the histological expression of CD133 in 142 cases of ccRCC. According to their results, 5-year disease-specific survival (DSS) was 90\% for patients with high expression of CD133, while DSS for patients with low expression of CD133 was 71\%. Progression-free survival (PFS) after 5 years was also higher for CD133-high (83\%) than for CD133-low patients (66\%). They concluded that low expression of CD133 is an independent predictor of poor DSS and PFS [47]. Unfortunately, information about CD133 from different sources is not consistent, and therefore further studies are in order.

\section{ALDH 1}

ALDH1 has been recognised as a general marker of both normal stem cells and CSCs $[26,48]$. Since, ALDH1-positive cells have stem cell-like characteristics it has been used as a CSC marker in many different types of cancer, including lung malignant melanoma, breast, bladder, prostate, and pancreas [49-53]. Moreover, it has been reported that high ALDH1 expression in breast cancer is associated with poor clinical prognosis because of positive correlation between ALDH1 and drug resistance. Also, it was reported that ALDH1 expression is correlated with tumour grade in RCC [54]. Ueda et al. showed in their experiments that ADLH1-positive cells have greater sphere forming ability and tumourigenicity than ALDH1-negative cells. Moreover, experiments performed by Ueda et al. on ALDH1-positive cells were done under hypoxic conditions and exposure to drugs resulting in 2- to 3 -fold increased numbers of ALDH1 positive cells. They concluded that ALDH1-positive cells are resistant to conventional therapies for RCC [55]. Abourbih et al. performed a microarray experiment on 244 RCC specimens. They concluded that ALDH1 expression has no correlation to tumour or stage, but in the metastatic setting the expression of $\mathrm{ALDH} 1$ is reduced. The expression pattern of ALDH1 in cCRCC might be useful for pathological classification of renal tumours, but in RCC ALDH1 cannot be used as a prognostic marker [56]. Further studies are needed to determine the relationship between ALDH1 and clinical prognosis in RCC.

\section{CXCR4}

CXCR4 is significantly related to the biological features of the tumour (stage, Fuhrman grade, clinical presentation) and DFS [57]. Zagzag et al. showed that CXCR4 mRNA is upregulated in kidney cancer samples when compar- 
ed to adjacent normal tissue [58]. Wang et al. examined 97 patients with RCC; 60 of them expressed CXCR4 at a high level, and 37 expressed CXCR4 at a low level. Expression of CXCR4 was correlated with poor prognosis [59]. Moreover, Li et al. examined 104 tumour samples; CXCR4 expression was found in 68 of them. In this experiment high expression of CXCR4 was associated with reduced overall survival [60]. There is growing evidence that the SDF-1/CXCR4 axis is important for tumour proliferation, survival, vascularisation, and metastasis. All the experiments listed above prove that CXCR4 may be a useful prognostic marker and therapeutic target and its expression is correlated with poor outcome for patients with RCC.

\section{CD44}

CD44 is overexpressed in many human malignancies, including breast, stomach, colorectal, lung, bladder, nonHodgkin lymphoma, certain squamous cell carcinomas, melanoma, and RCC [37]. Noroozinia et al., in their studies on 64 tissue samples, showed that 30 specimens were CD44-positive, and there was no connection between CD44 and tumour size and grade [61]. There is, however, an association between CD44 and tumour progression, recurrence, and aggressiveness [36, 37]. What is more, Moskvina et al. concluded, after evaluation of specimens of 105 RCC, that CD44 is an independent unfavourable factor to predict RCC: hyperexpression of CD44 resulted in a 52\% decrease in 5-year estimated survival rate [62]. In contrast to Noroozinia et al., Zhang et al. found a significant connection between CD44 and tumour size, grade, stage, and histological type. Moreover, they stated that CD44 might serve as a predictor of the number of metastatic sites [63]

\section{NCAM}

Cirović et al. concluded that NCAM seems to be present on RCC tissue regardless of histological type; however, NCAM expression is associated with tumour nuclear grade in CCRCC, so NCAM is not a useful marker for differential diagnosis of RCC, but its expression is correlated with aggressive behaviour and metastatic potential [64]. In a study performed by Daniel et al., in which they performed a retrospective immunohistochemical analysis of NCAM expression both in 338 primary renal tumours (including 249 conventional RCCs) and 31 metastases of conventional RCCs, they found association between NCAM expression and tumour size, Fuhrman grading, and lower survival rate. Finally, expression correlated with a higher risk of adrenal and CNS metastases [41].

\section{CAIX}

Carbonic anhydrase IX (CAIX) is a transmembrane member of the carbonic anhydrase family that catalyses the reversible hydration of carbon dioxide into bicarbonate and a proton. This reaction enables tumour cells to survive in an acidic microenvironment by maintaining a neutral $\mathrm{pH}$. Carbonic anhydrase IX is expressed in most ccRCCS through HIF-1 $\alpha$ accumulation driven by hypoxia and inactivation of the VHL gene; however, it is not expressed in healthy renal tissue [65].
It is widely believed that decreased CAIX levels are associated with poor survival in RCC. Many researchers support this idea [65-67]; however, Zghan et al. examined 730 specimens of cCRCC in which 708 were CAIX positive. One hundred and sixty-three tumours had low ( $\leq 85 \%)$ expression and 567 had high (> 85\%) expression of CAIX. There were 265 RCC-specific deaths. The median, follow-up for the 247 patients still under observation was 13.8 years. They concluded that low CAIX expression is not statistically significantly associated with RCC death or distant metastases; therefore, CAIX is not an independent marker for cCRCC [68].

Even though some of the molecular markers offer to be promising prognostic or isolation markers, there is still much to learn about them. Moreover, there is a need for further research of known molecular markers, as well as for searching for novel ones. In order to obtain more specific information and more reliable clinical prognosis from molecular markers there might be an imminent need for designing a broad spectrum of experiments focusing on combinations of different markers.

\section{Future perspectives}

The majority of renal TPC studies concern their identification by cell surface markers, which have been used to isolate TPCs from other tumours. We already know from pathology that kidney is an organ with a completely different surface marker expression pattern, and attempts of direct translation of methodology from other tumours often give contradictory results. Cancer stem cell populations should be evaluated using functional assays, cell membrane marker analysis, and finally genetic and epigenetic signatures in combination. More large-scale research is needed. Identification of renal TPCs using a specific set of markers remains a major challenge. Moreover, It is not clear whether TPCs exist in a relatively stable or a dynamic state - this highlights the role of the dedifferentiation process and epigenetic alterations in the sought cell population.

Another limitation in the search for TPCs in patient samples is intratumoural heterogeneity. In the Gerlinger et al. study [69] exome sequencing, chromosome aberration analysis, and ploidy profiling were performed on multiple samples obtained from primary and metastatic RCC. From $63 \%$ to $69 \%$ of all somatic mutations were not detectable within each tumour region. Various heterogeneities have been observed in mTOR kinase, and many tumour suppressor genes which induce loss of function: PTEN, SETD2, and KDM5C. The characteristics of the found mutations suggest convergent phenotypic evolution because of their distinct and spatially separated features. In a search for good and poor prognostic factors the signatures of gene expression were different within various regions of the same tumour. Further allelic composition and ploidy profiling analysis confirmed intratumoural heterogeneity an allelic imbalance profile was detected as well as ploidy heterogeneity [69]. More specific analysis of clear cell renal cell carcinoma (ccRCC) showed that intratumoural heterogeneity increased with the number of analysed biopsies [70]. The phenomenon of intratumoural hetero- 
geneity and cancer drug resistance was also described by Yap et al. [71] as the model of a Darwinian tree with a trunk. To conclude the data about intratumoural heterogeneity, this phenomenon casts doubt on results obtained from single-tumour biopsies. Developed targeted therapy approaches should be validated once again in large-scale and multi-sample studies. The presence of various tumour genetic profiles (in other words different tumour varieties) within the tumour induces therapeutic failure through Darwinian selection.

The authors declare no conflict of interest.

This work was supported by NCN Grant No. UMO-2011/ 01/B/NZ5/02822.

\section{References}

1. NCl. Definition of renal cell cancer. http://www.cancer.gov/dictionary?cdrid $=44988$

2. Chow WH, Dong LM, Devesa SS. Epidemiology and risk factors for kidney cancer. Nat Rev Urol 2010; 7: 245-57.

3. Buczek M, Escudier B, Bartnik E, Szczylik C, Czarnecka A. Resistance to tyrosine kinase inhibitors in clear cell renal cell carcinoma: from the patient's bed to molecular mechanisms. Biochim Biophys Acta 2014; 1845: 31-41.

4. Mattei J, da Silva RD, Sehrt D, Molina WR, Kim FJ. Targeted therapy in metastatic renal carcinoma. Cancer Lett 2014; 343: 156-60.

5. Diamond E, Riches J, Faltas B, Tagawa ST, Nanus DM. Immunologics and chemotherapeutics for renal cell carcinoma. Semin Intervent Radiol 2014; 31: 91-7.

6. Shiozawa Y, Nie B, Pienta KJ, Morgan TM, Taichman RS. Cancer stem cells and their role in metastasis. Pharmacol Ther 2013; 138: 285-93.

7. Blagosklonny MV. Cancer stem cell and cancer stemloids: from biology to therapy. Cancer Biol Ther 2007; 6: 1684-90.

8. Bansal N, Banerjee D. Tumor initiating cells. Curr Pharm Biotechnol 2009; 10: 192-6.

9. Warrington K, Hillarby MC, Li C, Letarte M, Kumar S. Functional role of CD105 in TGF-beta1 signalling in murine and human endothelial cells. Anticancer Res 2005; 25: 1851-64.

10. Gougos A, St Jacques S, Greaves A, et al. Identification of distinct epitopes of endoglin, an RGD-containing glycoprotein of endothelial cells, leukemic cells, and syncytiotrophoblasts. Int Immunol 1992; 4: 83-92.

11. Lastres P, Bellon T, Cabañas C, Sanchez-Madrid F, Acevedo A, Gou gos $A$, Letarte $M$, Bernabeu C. Regulated expression on human macrophages of endoglin, an Arg-Gly-Asp-containing surface an tigen. Eur J Immunol 1992; 22: 393-7.

12. Li C, Hampson IN, Hampson L, Kumar P, Bernabeu C, Kumar S. CD105 antagonizes the inhibitory signaling of transforming growth factor beta1 on human vascular endothelial cells. FASEB 2000; 14: 55-64.

13. Corbeil D, Roper K, Fargeas CA, Joester A, Huttner WB. Prominin: a story of cholesterol, plasma membrane protrusions and human pathology. Traffic 2001; 2: 82-91.

14. Fargeas CA, Joester A, Missol-Kolka E, Hellwig A, Huttner WB, Corbeil D. Identification of novel Prominin-1/CD133 splice variants with alternative $\mathrm{C}$-termini and their expression in epididymis and testis. J Cell Sci 2004; 117: 4301-11.

15. Mizrak D, Brittan M, Alison M. CD133: molecule of the moment. J Pathol 2008; 214: 3-9.

16. Yin AH, Miraglia S, Zanjani ED, et al. AC133, a novel marker for human hematopoietic stem and progenitor cells. Blood 1997; 90: 5002-12.

17. Bussolati B, Collino F, Camussi G. CD133+ cells as a therapeutic target for kidney diseases. Expert Opin Ther Targets 2012; 16: 157-65.
18. Florek M, Bauer N, Janich P et al. Prominin-2 is a cholesterol-binding protein associated with apical and basolateral plasmalemmal protrusions in polarized epithelial cells and released into urine. Cell Tissue Res 2007; 328: 31-47.

19. Bourseau-Guilmain E, Griveau A, Benoit J-P, Garcion E. The importance of the stem cell marker prominin-1/CD133 in the uptake of transferrin and in iron metabolism in human colon cancer Caco-2 cells. PloS One 2011; 6: e25515.

20. Neuzil J, Stantic M, Zobalova R, et al. Tumour-initiating cells vs. cancer 'stem' cells and CD133: what's in the name? Biochem Biophys Res Commun 2007; 355: 855-9.

21. Bussolati B, Bruno S, Grange C, Ferrando U, Camussi G. Identification of a tumor-initiating stem cell population in human renal carcinomas. FASEB J 2008; 22: 3696-705.

22. Bruno S, Bussolati B, Grange C, Collino F, Graziano ME, Ferrando U, Camussi G. CD133+ renal progenitor cells contribute to tumor angiogenesis. Am J Pathol 2006; 169: 2223-35.

23. Douville J, Beaulieu R, Balicki D. ALDH1 as a functional marker of cancer stem and progenitor cells. Stem Cells Dev 2009; 18: 17-25.

24. Hess DA, Wirthlin L, Craft TP, et al. Selection based on CD133 and high aldehyde dehydrogenase activity isolates long-term reconstituting human hematopoietic stem cells. Blood 2006; 107: 2162-9.

25. Hess DA, Meyerrose TE, Wirthlin L, Craft TP, Herrbrich PE, Creer MH, Nolta JA. Functional characterization of highly purified human hematopoietic repopulating cells isolated according to aldehyde dehydrogenase activity. Blood 2004; 104: 1648-55.

26. Marcato P, Dean CA, Pan D, et al. Aldehyde dehydrogenase activity of breast cancer stem cells is primarily due to isoform ALDH1A3 and its expression is predictive of metastasis. Stem Cells 2011; 29: 32-45.

27. Armstrong L, Stojkovic M, Dimmick I, Ahmad S, Stojkovic P, Hole N, Lako M. Phenotypic characterization of murine primitive hematopoietic progenitor cells isolated on basis of aldehyde dehydrogenase activity. Stem Cells 2004; 22: 1142-51.

28. Pearce DJ, Taussig D, Simpson C, Allen K, Rohatiner AZ, Lister TA Bonnet D. Characterization of cells with a high aldehyde dehydrogenase activity from cord blood and acute myeloid leukemia samples. Stem Cells 2005; 23: 752-60.

29. Skommer J, Wlodkowic D, Pelkonen J. CXCR4 expression during tumour cell death. Leuk Res 2007; 31: 1155-6.

30. Vicari AP, Caux C. Chemokines in cancer. Cytokine Growth Factor Rev 2002; 13: 143-54.

31. Taichman RS, Cooper C, Keller ET, Pienta KJ, Taichman NS, McCauley LK. Use of the stromal cell-derived factor-1/CXCR4 pathway in prostate cancer metastasis to bone. Cancer Res 2002; 62: 1832-7.

32. Müller A, Homey B, Soto H, et al. Involvement of chemokine receptors in breast cancer metastasis. Nature 2001; 410: 50-6.

33. Greubern EK, Smith-Pearson P, Wang J, Pendergast AM. Role of ABL family kinases in cancer: from leukemia to solid tumors. Nat Rev Cancer 2013; 13: 559-71.

34. Ueland J, Yuan A, Marlier A, Gallagher AR, Karihaloo A. A novel role for the chemokine receptor $\mathrm{Cxcr} 4$ in kidney morphogenesis: an in vitro study. Dev Dyn 2009; 238: 1083-91.

35. Ruoslahti E. The Walter Herbert Lecture. Control of cell motility and tumour invasion by extracellular matrix interactions. Br J Cancer 1992; 66: 239-42.

36. Tawfik OW, Kramer B, Shideler B, Danley M, Kimler BF, Holzbeierlein J. Prognostic significance of CD44, platelet-derived growth factor receptor alpha, and cyclooxygenase 2 expression in renal cell carcinoma. Arch Pathol Lab Med 2007; 131: 261-7.

37. Rioux-Leclercq N, Epstein JI, Bansard JY, et al. Clinical significance of cell proliferation, microvessel density, and CD44 adhesion molecule expression in renal cell carcinoma. Hum Pathol 2001; 32: 1209-15.

38. Nouwen EJ, Dauwe S, van der Biest I, De Broe ME. Stage- and segment-specific expression of cell-adhesion molecules N-CAM, A-CAM, and L-CAM in the kidney. Kidney Int 1993; 44: 147-58.

39. Abbate M, Brown D, Bonventre JV. Expression of NCAM recapitulates tubulogenic development in kidneys recovering from acute ischemia. Am J Physiol 1999; 277 (3 Pt 2): F454-63.

40. Garin-Chesa P, Fellinger EJ, Huvos AG, Beresford HR, Melamed MR, Triche TJ, Rettig WJ. Immunohistochemical analysis of neural cell adhesion molecules. Differential expression in small round cell tumors of childhood and adolescence. Am J Pathol 1991; 139: 275-86. 
41. Daniel L, Bouvier C, Chetaille B, et al. Neural cell adhesion molecule expression in renal cell carcinomas: relation to metastatic behavior. Hum Pathol 2003; 34: 528-32.

42. Rink M, Chun FKH, Robinson B, et al. Tissue-based molecular markers for renal cell carcinoma. Minerva Urol Nefrol 2011; 63: 293-308.

43. Minardi D, Lucarini G, Mazzucchelli R, et al. Prognostic role of Fuhrman grade and vascular endothelial growth factor in ptla clear cell carcinoma in partial nephrectomy specimens. J Uro 2005; 174: 1208-12.

44. Dubinski W, Gabril M, lakovlev VV, et al. Assessment of the prognostic significance of endoglin (CD105) in clear cell renal cell carcinoma using automated image analysis. Hum Pathol 2012; 43: 1037-43.

45. D’Alterio C, Cindolo L, Portella L, et al. Differential role of CD133 and CXCR4 in renal cell carcinoma. Cell Cycle 2010; 9: 4492-500.

46. Kim K, Ihm H, Ro JY, Cho YM. High-level expression of stem cell marker CD133 in clear cell renal cell carcinoma with favorable prognosis. Oncol Lett 2011; 2: 1095-100.

47. Costa WHd, Rocha RM, Cunha IW, Fonseca FP, Guimaraes GC, Zequi Sde C. CD133 immunohistochemical expression predicts progression and cancer-related death in renal cell carcinoma. World J Urol 2012; 30: 553-8.

48. Ma I, Allan AL. The role of human aldehyde dehydrogenase in normal and cancer stem cells. Stem Cell Rev 2011; 7: 292-306.

49. Ma S, Chan KW, Lee TK, Tang KH, Wo JY, Zheng BJ, Guan XY. Aldehyde dehydrogenase discriminates the CD133 liver cancer stem cell populations. Mol Cancer Res 2008; 6: 1146-53.

50. Jiang F, Qiu Q, Khanna A, et al. Aldehyde dehydrogenase 1 is a tumor stem cell-associated marker in lung cancer. Mol Cancer Res 2009; 7: 330-8.

51. Ginestier C, Hur MH, Charafe-Jauffret E, et al. ALDH1 is a marker of normal and malignant human mammary stem cells and a predic tor of poor clinical outcome. Cell Stem Cell 2007; 1: 555-67.

52. Kim MP, Fleming JB, Wang $\mathrm{H}$, et al. ALDH activity selectively defines an enhanced tumor-initiating cell population relative to CD133 expression in human pancreatic adenocarcinoma. PLoS One 2011; 6: e20636.

53. van den Hoogen C, van der Horst G, Cheung $\mathrm{H}$, et al. High aldehyde dehydrogenase activity identifies tumor-initiating and metastasis-initiating cells in human prostate cancer. Cancer Res 2010; 70: 5163-73.

54. Ozbek E, Calik G, Otunctemur A, Aliskan T, Cakir S, Dursun M, Somay A. Stem cell markers aldehyde dehydrogenase type 1 and nestin expressions in renal cell cancer. Arch Ital Urol Androl 2012; 84: 7-11.

55. Ueda K, Ogasawara S, Akiba J, et al. Aldehyde dehydrogenase 1 identifies cells with cancer stem cell-like properties in a human renal cell carcinoma cell line. PLoS One 2013; 8: e75463.

56. Abourbih S, Sircar K, Tanguay S, Kassouf W, Aprikian A, Mansure J, Brimo F. Aldehyde dehydrogenase 1 expression in primary and metastatic renal cell carcinoma: an immunohistochemistry study. World J Surg Oncol 2013; 11: 298.

57. Ottaiano A. Finding markers for cancer stem cells in renal cell carcinoma: looking beyond CD133. Cell Cycle 2010; 9: 4431.

58. Zagzag D, Krishnamachary B, Yee H, Okuyama H, Chiriboga L, Ali MA, Melamed J, Semenza GL. Stromal cell-derived factor1alpha and CXCR4 expression in hemangioblastoma and clear cell-renal cell carcinoma: von Hippel-Lindau loss-of-function induces expression of a ligand and its receptor. Cancer Res 2005; 65: 6178-88.

59. Wang L, Chen W, Gao L, Yang Q, Liu B, Wu Z, Wang Y, Sun Y. High expression of CXCR4, CXCR7 and SDF-1 predicts poor survival in renal cell carcinoma. World J Surg Oncol 2012; 10: 212.

60. Li G, Badin G, Zhao A, Gentil-Perret A, Tostain J, Péoc'h M, Gigante M. Prognostic value of CXCR4 expression in patients with clear cell renal cell carcinoma. Histol Histopathol 2013; 28: 1217-22.

61. Noroozinia F, Fahmideh AN, Yekta Z, Rouhrazi H, Rasmi Y. Expres sion of CD44 and P53 in renal cell carcinoma: association with tumor subtypes. Saudi J Kidney Dis Transpl 2014; 25: 79-84.

62. Moskvina LV, Andreeva II, Frank GA, Zavalishina LÉ, Petrov AN, Mal'kov PG. Prognostic value of the expression of adhesion molecules for non-clear-cell variants of renal cell carcinoma. Ark Patol 2013; 75: 3-8.
63. Zhang Y, Sun B, Zhao X, Liu Z, Wang X, Yao X, Dong X, Chi J. Clinical significances and prognostic value of cancer stem-like cells markers and vasculogenic mimicry in renal cell carcinoma. J Surg Oncol 2013; 108: 414-9.

64. Cirović SL, Cegar BS, Vjestica JM, et al. Expression of neural cell adhesion molecule in renal cell carcinoma. Acta Chir lugosl 2012; 59: 39-44.

65. Tostain J, Li G, Gentil-Perret A, Gigante M. Carbonic anhydrase 9 in clear cell renal cell carcinoma: a marker for diagnosis, prognosis and treatment. Eur J Cancer 2010; 46: 3141-8.

66. Bui MHT, Seligson D, Han KR, et al. Carbonic anhydrase IX is an independent predictor of survival in advanced renal clear cell carcinoma: implications for prognosis and therapy. Clin Cancer Res 2003; 9: 802-11.

67. Phuoc NB, Ehara H, Gotoh T, Nakano M, Kamei S, Deguchi T, Hirose Y. Prognostic value of the co-expression of carbonic anhydrase IX and vascular endothelial growth factor in patients with clear cell renal cell carcinoma. Oncol Rep 2008; 20: 525-30.

68. Zhang BY, Thompson RH, Lohse CM, Dronca RS, Cheville JC, Kwon ED, Leibovich BC. Carbonic anhydrase IX (CAIX) is not an independent predictor of outcome in patients with clear cell renal cell carcinoma (ccRCC) after long-term follow-up. BJU Int 2013; 111: 1046-53.

69. Gerlinger M, Rowan AJ, Horswell S, et al. Intratumor heterogeneity and branched evolution revealed by multiregion sequencing. N Engl J Med 2012; 366: 883-92.

70. Gerlinger M, Horswell S, Larkin J, et al. Genomic architecture and evolution of clear cell renal cell carcinomas defined by multiregion sequencing. Nat Genet 2014; 46: 225-33.

71. Yap TA, Gerlinger M, Futreal PA, Pusztai L, Swanton C. Intratumor heterogeneity: seeing the wood for the trees. Sci Transl Med 2012; 4: $127 p s 110$.

\section{Address for correspondence}

\section{Damian Matak}

Department of Oncology with Laboratory of Molecular Oncology

Military Institute of Medicine

Szaserów 128

04-141 Warsaw, Poland

e-mail:dmatak@wim.mil.pl 